
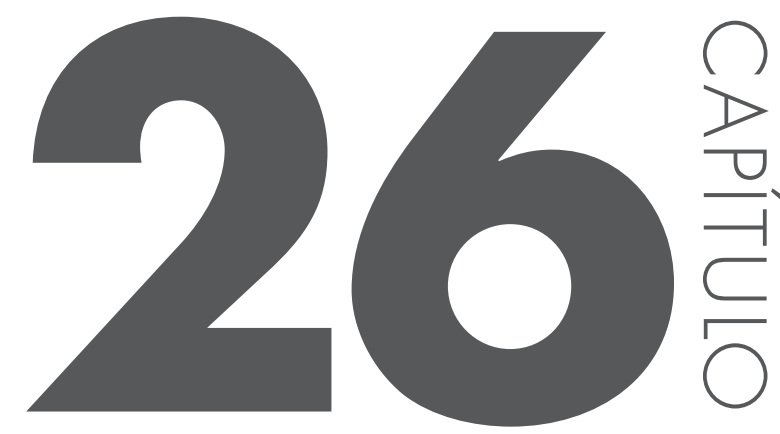

\title{
EFEITOS DA DESNUTRICÃO NO TRATO GASTRINTESTINAL
}

Emmanuel Prata de Souza Pedro Marcos Gomes Soares Ítalo Leite Figueiredo Juliana Magalhães da Cunha Rêgo Reinaldo Barreto Oriá

\subsection{DESNUTRIC̣ÃO E EPIDEMIOLOGIA}

A literatura médica define a desnutrição como um distúrbio do estado nutricional em que um ou mais nutrientes essenciais estão faltando ou há em quantidades insuficientes. A expressão desnutrição energético-proteica (DEP) é o termo adotado pela Organização Mundial de Saúde (OMS) para designar essa síndrome. A DEP é altamente prevalente entre as crianças com menos de cinco anos de idade em regiões em desenvolvimento de todo o mundo, sendo responsável por 2,2 milhões de mortes por ano. De acordo com a OMS, em 2013, as estimativas em países de baixa e média renda (LMIC) apontaram 161 milhões de crianças menores de cinco 
anos de idade com déficit de crescimento corporal, 99 milhões abaixo do peso, e 51 milhões em DEP extrema (défice de peso por altura) (Figura 26.1).

A desnutrição está diretamente associada com taxas de pobreza, escassez de alimentos, dificuldade no acesso a serviços de saúde, superpopulação, falta de higiene, de saneamento básico e insegurança alimentar, muito prevalentes em países mais pobres, especialmente na África Subsaariana e algumas regiões da Ásia. Um agravante é a contaminação pelo vírus HIV na África Subsaariana, que pode aumentar o risco de mortalidade infantil em até $80 \%$ em crianças desnutridas.

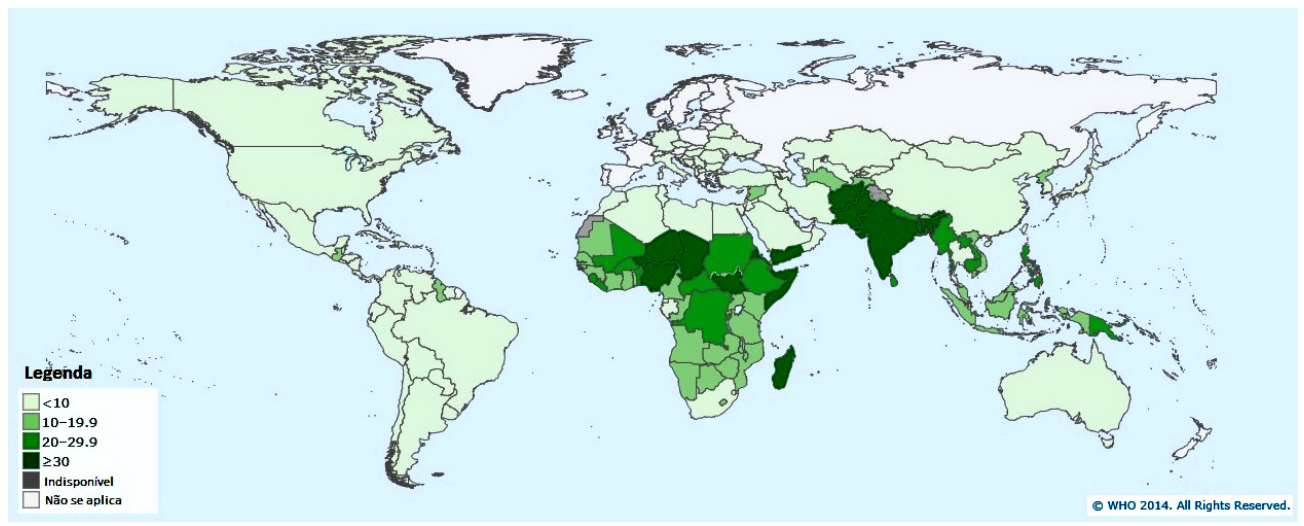

Figura 26.1 - Distribuição mundial (\%) de crianças menores de cinco anos de idade abaixo do peso.

Adaptado de GHO/WHO (2015). Underweight in children. Disponível em:

http://gamapserver.who.int/gho/interactive_charts/MDGl/tablet/atlas.html

Cerca de $17 \%$ das crianças nos países em desenvolvimento estão abaixo do peso para a idade, de acordo com os padrões de crescimento infantil da OMS. A prevalência de baixo peso é maior na região do Sul da Ásia (30\%), seguida da África Ocidental (21\%), Oceania e África Oriental (ambos 19\%), do Sudeste da Ásia e da África Oriental (ambos 16\%) e África do Sul (12\%). A prevalência para as regiões da América Latina Oriental e Central, Oeste da Ásia, Norte da África e do Caribe foi abaixo de $10 \%$.

As crianças com DEP podem apresentar reduzida aptidão física e intelectual, associada com baixa escolaridade. Para as mulheres com DEP, o risco de gerar neonatos com baixo peso aumenta, perpetuando assim o ciclo vicioso para as gerações seguintes. A DEP infantil é ainda mais agravada pela amamentação insu-ficiente e deficiência de vitamina A e zinco, importantes nutrientes tróficos intes-tinais, que atuam melhorando a integridade da barreira intestinal e melhorando a resposta imunológica contra infecções. Somando-se a isso, pacientes clínicos ou cirúrgicos em vários países industrializados podem apresentar algum grau de des- 
nutrição proteico-calórica. Pacientes com desnutrição geralmente permanecem mais tempo hospitalizados o que aumenta os custos com cuidados médicos.

A DEP resulta do consumo inadequado de proteínas e calorias, ou, ainda, de deficiências na digestão ou absorção desses nutrientes, culminando com a perda de tecido gorduroso e muscular, perda de peso, letargia e fraqueza generalizada. As alterações são sistêmicas e inespecíficas, levando a distúrbios no eixo GHIGF-1 no controle da função da placa epifisária, redução da atividade dos osteoblastos, insuficiência na formação de colágeno, atrofia das glândulas endócrinas (testículos e ovários), atrofia do timo e dos tecidos linfoides, degeneração gordurosa no fígado, anemia e edema por hipoproteinemia.

A desnutrição aguda, chamada de "wasting", é definida por um reduzido escore z do peso-por altura-por idade (WHZ) (Tabela 26.1).

Tabela 26.1 - Classificação da desnutrição de acordo com o escore z de peso-por altura- -por idade (WHZ).

\begin{tabular}{|l|l|}
\hline Classificação & Valores de escore $-\mathrm{z}$ \\
\hline Normal & escore $\mathrm{z} \geq-1,0 \mathrm{DP}$ \\
\hline Leve & $-2,0 \leq$ escore $\mathrm{z}<-1,0 \mathrm{DP}$ \\
\hline Moderada & $-3,0 \leq$ escore $\mathrm{z}<-2,0 \mathrm{DP}$ \\
\hline Severa & escore $\mathrm{z}<-3,0 \mathrm{DP}$ \\
\hline
\end{tabular}

* segundo população de referência definida pela Organização Mundial de Saúde (OMS), disponível em: (http://www.who.int/ childgrowth/software/en/). DP = desvio-padrão

Existem três categorias da desnutrição severa, com um quadro clínico mais bem descrito: o marasmo, o kwashiorkor e kwashiorkor marasmático. O marasmo é um estado crônico, com deficiência calórica, perda da gordura e da proteína corpórea e edema. O kwashiorkor ocorre pela deficiência de proteína na dieta por um longo período, dessa forma, se apresentando com maior edema, devido à redução da pressão coloidosmótica intravascular, por conta da hipoalbuminemia, o que pode mascarar a perda de peso. O kwashiorkor marasmático é a forma bem mais severa e com características comuns das duas condições, podendo ocorrer após trauma, sepse e doença inflamatória crônica. O Quadro 26.1 mostra as principais características do quadro clínico do marasmo e kwashiorkor. 
Quadro 26.1 - Aspectos clínicos da desnutrição grave em crianças

\begin{tabular}{|l|l|}
\hline KWASHIORKOR & MARASMO \\
\hline Prevalência e incidência maior em crianças menores de 2 anos & Prevalência e incidência maior em crianças maiores de 2 anos \\
\hline Deprivação predominantemente proteica & $\begin{array}{l}\text { Deprivação crônica de macronutrientes } \\
\text { Infecç̃oes recorrentes }\end{array}$ \\
\hline Atrofia muscular grave sem perda de gordura subcutânea & Hipotrofia muscular com parcial perda de gordura subcutânea \\
\hline Edema importante, anasarca & Edema discreto \\
\hline $\begin{array}{l}\text { Altura e peso compatíveis com a idade } \\
\text { Pele descamativa, dermatite com áreas confluentes de } \\
\text { hiperpigmentação e hiperceratose } \\
\text { Cabelo hipopigmentado, alopécia } \\
\text { Hipotermia }\end{array}$ & $\begin{array}{l}\text { Altura e peso incompatíveis com a idade } \\
\text { Pele descamativa, dobras cutâneas redundantes por perda do } \\
\text { panículo adiposo } \\
\text { Cabelo esparso, sem alteração de pigmentação } \\
\text { Bradicardia, hipotensão, hipotermia, Anorexia nervosa }\end{array}$ \\
\hline Esteatose & Ausência de esteatose \\
\hline $\begin{array}{l}\text { Hipoalbuminemia, aumento dos níveis séricos de IL-6, proteína } \\
\text { C reativa, redução de IGF-1, hipercortisolismo }\end{array}$ & $\begin{array}{l}\text { Aumento menos evidente dos níveis séricos de IL-6, proteína C } \\
\text { reativa, redução de IGF-1, hipercortisolismo, hipoglicemia }\end{array}$ \\
\hline
\end{tabular}

Recentemente, tem se prestado mais atenção a uma condição muito prevalente em países em desenvolvimento, chamada de enteropatia ambiental (enteropatia tropical), uma síndrome multifatorial que afeta crianças residentes em áreas carentes, com precárias condiçōes de saneamento e higiene. Essa condição está associada à exposição continuada a colliformes fecais, com afecç̃ões recorrentes de doençás parasitárias.

Um fator importante (especialmente em crianças), na enteropatia tropical, é a incapacidade da absorção adequada de nutrientes. Nesse aspecto, infecções intestinais persistentes, mesmo assintomáticas, assumem um papel de destaque nessa fisiopatologia. Aventa-se que uma parte substancial da desnutrição global decorre do prejuízo da função absortiva intestinal, proveniente de infecções entéricas múltiplas e repetidas. Este fenômeno é chamado "ciclo vicioso da desnutrição e doenças entéricas” (Figura 26.2), com distúrbios na função imunológica e perda da integridade da barreira intestinal, predispondo ainda mais a recorrência de episódios de doenças entéricas (mesmo assintomáticas) e translocação bacteriana, levando a um estado inflamatório intestinal crônico, que culmina com a má absorção de nutrientes, amplificando e reiniciando o ciclo. Com o uso da terapia de reidratação oral e melhor acesso à saúde, a mortalidade por desnutrição e diarreia tem diminuído mundialmente, contudo, a desnutrição pode ser marginal (subnutrição) e negligenciada, levando a uma morbidade prolongada. 


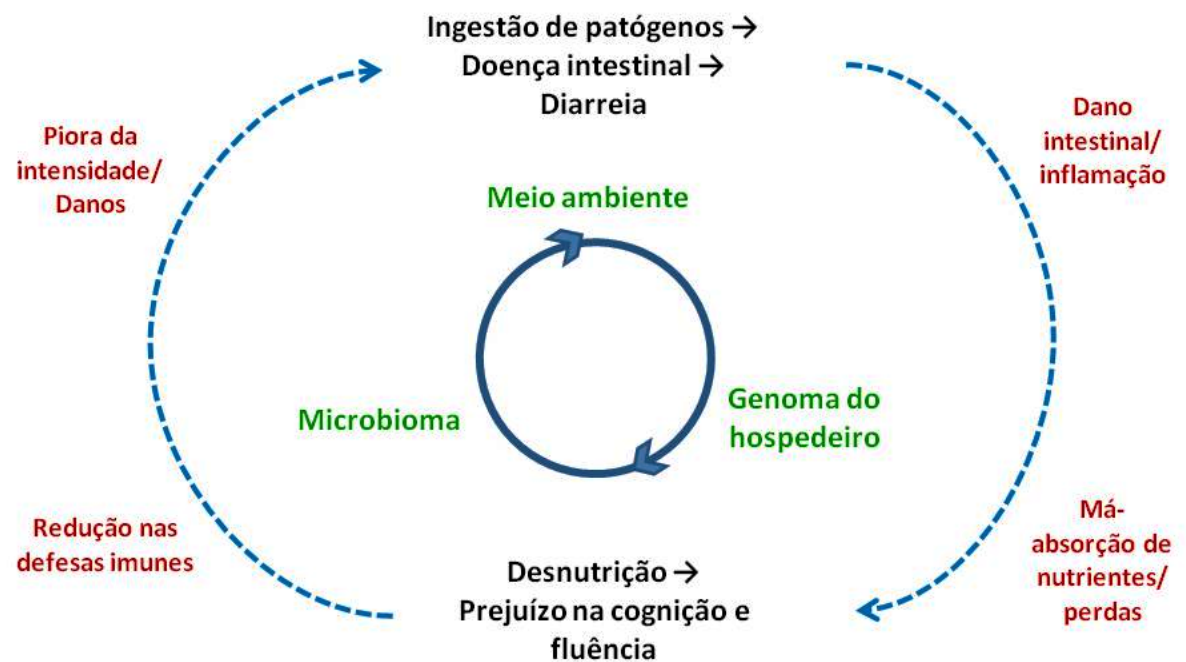

Figura 26.2 - Ciclo vicioso envolvendo diarreia e desnutrição, incluindo fatores intrínsecos e extrínsecos ao indivíduo e possíveis consequências.

\subsection{EFEITOS DA DESNUTRIC̣ÃO NA MUCOSA}

Na DEP ocorre redução da altura dos vilos e menor taxa de proliferação e migração epitelial no eixo cripta-vilo, culminando na diminuição da massa intestinal, com atrofia da mucosa. Em modelos animais de separação materna prolongada, atrofia de vilos e perda da integridade da borda em escova são achados importantes (Figura 26.3). A relação lipídio:proteína e colesterol:fosfolipídeo aumenta na borda em escova dos enterócitos, podendo levar a alterações de fluidez da membrana e diminuição da capacidade absortiva.

A quinase de células intestinais (ICK), uma superfamília de proteínas quinases ativadas por mitógeno, parece estar envolvida na resposta compensatória da mucosa intestinal à desnutrição, com o envolvimento de várias vias de sinalização para melhorar a viabilidade celular e redução da apoptose, incluindo à via ERK, AKT, e Wnt- $\beta$-catenina. 

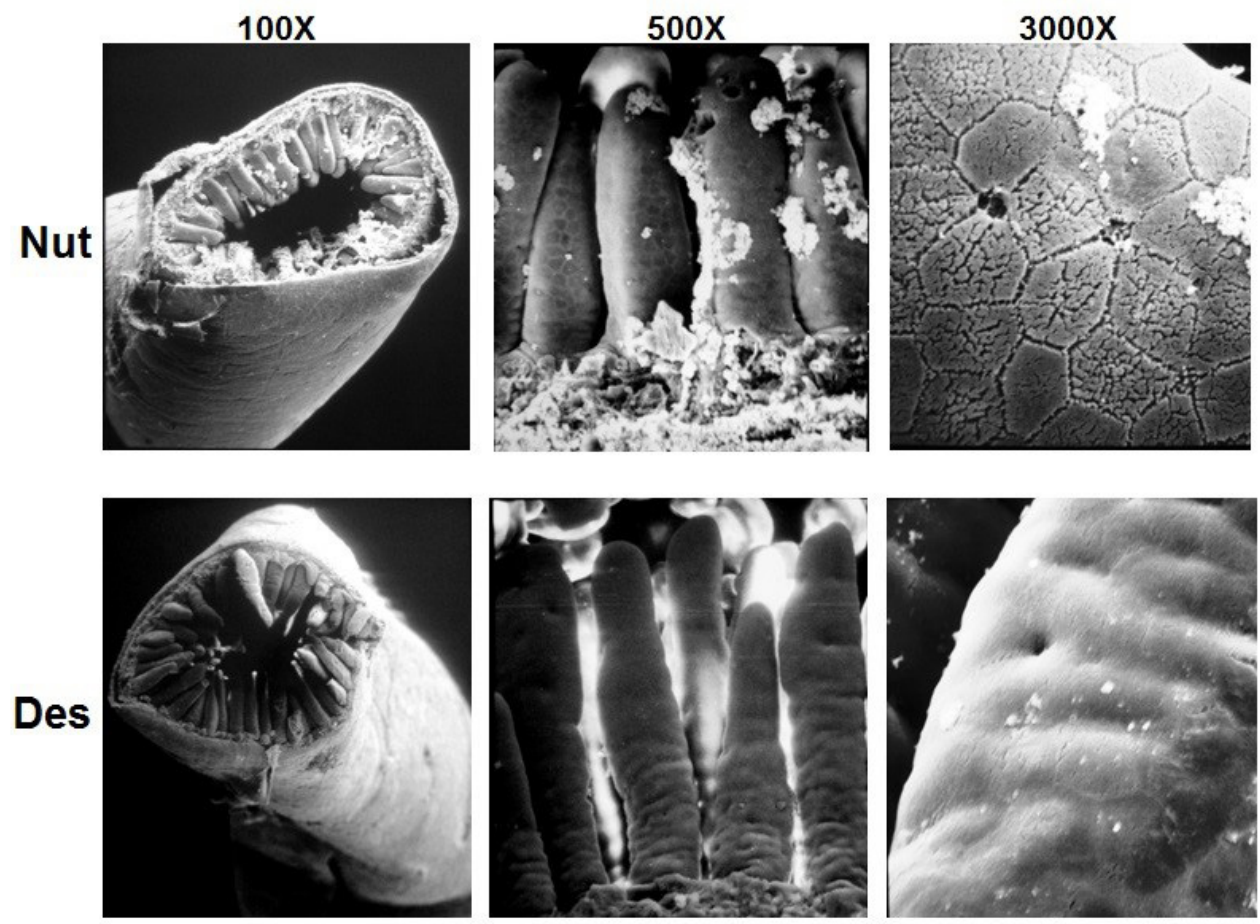

Figura 26.3 - Alteração da arquitetura de vilos e da superfície absortiva em camundongos C57BL6J de 14 dias de idade após desnutrição induzida por separação materna prolongada.

Legenda: Nut = Nutridos, sem separação materna; Des = Desnutridos, após separação materna. Notar atrofia de vilos e da borda em escova dos enterócitos. Imagens de microscopia eletrônica de varredura.

\subsection{EFEITOS DA DESNUTRIC̣ÃO NA IMUNIDADE INTESTINAL}

A DEP pode aumentar a susceptibilidade à translocação de endotoxinas e seus efeitos, afetando a permeabilidade intestinal, as propriedades biomecânicas e a função imunológica.

$\mathrm{Na}$ desnutrição severa pode ocorrer redução de IgA secretória na saliva. Além disso, pode ocorrer redução da acidez gástrica.

$\mathrm{O}$ aumento da colonização de bactérias patogênicas pode induzir alterações imunoinflamatórias na mucosa e aumento da permeabilidade intestinal. A atividade reduzida de granulócitos e outras células de defesa e diminuição das proteínas do sistema complemento podem ainda mais comprometer a resposta contra patógenos entéricos. Pode ocorrer diminuição nas populações de células T e B no 
sangue e nos tecidos linfoides que sofrem atrofia, incluindo o timo, responsável pela produção e liberação de células $\mathrm{T}$. A desnutrição tende a desviar a reposta imunológica para TH2 em vez de TH1. Entretanto, a presença de infecções podem aumentar a produção de citocinas pró-inflamatórias, especialmente IL-6 e TNF, com produção das proteínas de fase aguda pelo fígado, incluindo níveis séricos mais elevados da proteína $\mathrm{C}$ reativa, caracterizando um processo de inflamação sistêmica.

\subsection{DESNUTRIÇÃO E MICROBIOTA INTESTINAL}

A microbiota intestinal inclui uma vasta população de microorganismos, com cerca de 100 trilhões de células, dentre elas, as principais são membros do filo Firmicutes e Bacteroidetes. A desnutrição pode influenciar o microambiente do lúmen intestinal, favorecendo a disbiose, uma alteração do equilíbrio das populações bacterianas, especialmente com aumento das taxas de bactérias Gram-negativas em relação aos simbiontes Gram-positivos aeróbicos. A disbiose da microbiota, com redução de bactérias Gram-positivas, necessárias para o estímulo da secreção de IgA na mucosa intestinal, pode comprometer a quantidade de células CD4+, interferon- $\gamma$ (IFN- $\gamma$ ) e células T na mucosa, levando a uma limitação da resposta imune adaptativa.

Essa disbiose também pode favorecer a translocação bacteriana intestinal e, portanto, pode contribuir para uma doença inflamatória intestinal, com ou sem diarreia, que pode ser subclínica e prolongada. Além disso, essa disbiose pode influenciar a proliferação de patógenos entéricos, afetando a resposta imunológica do hospedeiro, ampliando o defeito da barreira intestinal e da superfície de absorção induzida pela desnutrição.

Estudos de transfecção da microbiota intestinal de crianças com kwashiorkor para camundongos gnobióticos mostraram maior perda de peso quando os animais receptores foram submetidos a uma dieta pobre em proteína, apresentando deficiência de populações de bactérias com caráter anti-inflamatório.

\subsection{EFEITOS DA DESNUTRIC̣ÃO SOBRE ENZIMAS DIGESTIVAS}

Algumas enzimas (incluindo as dissacaridases intestinais) que são críticas na digestão de nutrientes podem estar seriamente comprometidas na desnutrição. Uma hipótese para redução da atividade enzimática é o menor conteúdo de 
alimentos no tubo gastrointestinal, o que leva a menor estimulação/liberação de hormônios e neurotransmissores, como colecistoquinina, gastrina e acetilcolina.

A desnutrição pode afetar o pâncreas, reduzindo a quantidade de zimogênios armazenados nos ácinos pancreáticos. A atividade das enzimas lipase e tripsina está deprimida em cerca de 50 e $70 \%$, enquanto da amilase permanece inalterada. Quimiotripsina e carboxipeptidase $\mathrm{A}+\mathrm{B}$ têm suas atividades conservadas.

Novos alvos moleculares, como a via de sinalização AKT/mTOR (proteína quinase $\mathrm{B} /$ proteína alvo da rapamicina em mamíferos), vêm sendo investigados com o propósito de compreender o efeito da desnutrição na produção de enzimas pancreáticas.

No kwashiorkor, as enzimas hepáticas flavina oxidase, xantina oxidase e D-aminoácido oxidase estão reduzidas. A enzima ácido glicólico oxidase permanece inalterada.

\subsection{EFEITO DA DESNUTRIC̣ÃO NA ABSORC̣ÃO E SECREÇÃO INTESTINAL}

A DEP provoca efeitos drásticos na absorção e secreção do epitélio intestinal. Esses processos são regidos principalmente por cinco mecanismos-base (Figura 26.4), resumidos na sequência:

- Composição e fluidez da membrana dos microvilos de enterócitos: como as propriedades biofísicas das membranas são afetadas pela composição da dieta, é de se esperar que a desnutrição influencie o transporte iônico e a permeabilidade.

- Mudanças no potencial de membrana da borda em escova do enterócito: a desnutrição pode alterar o transporte de íons através de mudanças nas forças elétricas, aumentando a absorção de nutriente acoplado ao sódio e à secreção aumentada de cloreto.

- Alterações hormonais: o hormônio majoritário durante a desnutrição é o glucagon. Esse hormônio quando administrado intraperitonealmente aumenta o potencial de membrana em enterócitos.

- Influências neurais: o sistema nervoso entérico responde a estímulos físicos e químicos no lúmen intestinal. A ausência de glicose, por exemplo, ativa reflexos neurais entéricos que influenciam o transporte basal de íons.

- Estresse oxidativo: a desnutrição está também associada com o estresse na mucosa ao nível de enzimas e da produção de radicais livres. Assim, pode haver peroxidação lipídica e consequente dano às membranas dos enterócitos, levando a alterações nos canais iônicos, na permeabilidade de membrana e nas proteínas da junção de oclusão. 


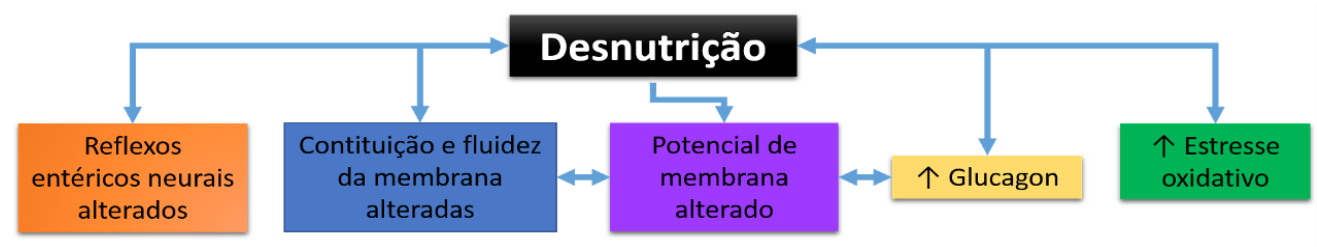

Figura 26.4 - Mecanismos das alterações de transporte de íons e fluidos induzidas pela desnutrição

$\mathrm{Na}$ desnutrição, geralmente, ocorre uma mudança no transporte basal de íons de um estado absortivo para um secretório. Isto resulta da elevação das correntes de curta condutância, necessárias para anular o potencial transepitelial espontâneo, alterando assim a direção das correntes iônicas, principalmente do íon cloreto $\left(\mathrm{Cl}^{-}\right)$. Uma vez alterada, essa força eletroquímica direciona o movimento de sódio para o lúmen e secreção de água.

A permeabilidade intestinal a íons e macromoléculas pode estar elevada na desnutrição, que aumenta o potencial para perdas de fluidos e eletrólitos. A atrofia da mucosa reduz a absorção de nutrientes, mas pode ser contrabalanceada pelo aumento da expressão de proteínas transportadoras (Ex.: PEPT-1 e GLUT-5) e pelo aumento do gradiente eletroquímico.

O Quadro 26.2 lista mudanças na função gastrintestinal que ocorrem durante a DEP ou privação de alimentos. 
Quadro 26.2 - Alterações da função gastrintestinal induzidas pela desnutrição

\begin{tabular}{|c|c|}
\hline & ALTERAC̣̃̃ES CAUSADAS PELA DEP NA FUNC̣̃̃O INTESTINAL \\
\hline Transporte basal de íons e fluidos & $\begin{array}{l}\text { - Diminuição da absorção de } \mathrm{Cl}^{-} \text {e } \mathrm{HCO}_{3}^{-} \\
\text {- Aumento da secreccão de ânions } \\
\text { - Secrecção de } \mathrm{Na}^{+} \text {(gradiente eletroquímico) } \\
\text { - Secrecção de } \mathrm{H}_{2} \mathrm{O} \text { (pressão osmótica) }\end{array}$ \\
\hline $\begin{array}{l}\text { Transporte estimulado } \\
\text { de íons e fluidos }\end{array}$ & $\begin{array}{l}\text { - Exacerbacãa da extensão e severidade dos sintomas da diarreia (sensibilidade aos agentes } \\
\text { secretórioś, p. ex., acetilcolina, prostaglandina E2, e enterotoxina termostável de E. coli) } \\
\text { - Idem ao transporte basal após presença de secretagogo (iniciando na secreção de } \mathrm{Cl}^{-} \text {) } \\
\text { - Aumento da absorção dos nutrientes acoplados ao } \mathrm{Na}^{+} \\
\text {(principalmente se átivados por adrenérgicos) }\end{array}$ \\
\hline $\begin{array}{l}\text { Permeabilidade de íons } \\
\text { e grandes solutos }\end{array}$ & $\begin{array}{l}\text { - Endocitose aumentada (a macromoléculas bem como a antígenos ou agentes nocivos) } \\
\text { - Transporte paracelular aumentado (80\% dos íons passam pela via paracelular) }\end{array}$ \\
\hline Transporte de carboidratos & $\begin{array}{l}\text { - Transportadores de glicose aumentados } \\
\text { - Glicose global diminui ou não altera (massa da mucosa diminui) }\end{array}$ \\
\hline $\begin{array}{l}\text { Transporte de aminoácidos } \\
\text { e peptídeos }\end{array}$ & - Transportadores de aminoácidos (principalmente para valina) e peptídeos aumentados \\
\hline Transporte de lipideos & - Diminuição da absorção e digestão de lipídeos \\
\hline $\begin{array}{l}\text { Transporte de vitaminas } \\
\text { e minerais }\end{array}$ & $\begin{array}{l}\text { - Diminuição da absorção de zinco } \\
\text { - Aumento da absorção de cálcio } \\
\text { - Diminuicção da absorção de vitamina A }\end{array}$ \\
\hline
\end{tabular}

Além do transporte basal, a desnutrição aumenta a resposta do epitélio a agentes que estimulam a secreção de íons e fluidos. Dentre esses agentes incluem-se a enterotoxina da Escherichia coli, e a antígenos secretórios como a b-lactoglobulina. Assim, a DEP predispõe o indivíduo a diarreia ou potencializa sua severidade.

\subsection{CONCLUSÃO}

O impacto da desnutrição (especialmente pelas alterações da programação genética e epigenéticas) é ainda pouco compreendido, apesar de muitos estudos apontarem para uma forte contribuição para o risco de doenças metabólicas, doenças cardiovasculares e doenças crônico-degenerativas. A desnutrição asso-ciada com doenças entéricas recorrentes pode levar à atrofia da mucosa intestinal, deficiência imunológica, alteração da barreira epitelial e má-absorção de nutrien-tes, que podem amplificar ainda mais o ciclo, com uma doença inflamatória que pode ser crônica e subclínica (mesmo sem diarreia), contribuindo para o aumento da taxa global do escore de anos perdidos por incapacitação, reduzindo o poten-cial genético de um indivíduo e o capital humano de uma sociedade.

A compreensão da fisiopatologia do ciclo vicioso da desnutrição e de co-morbidades no trato gastrintestinal é crítica para desenvolver estratégias te- 
rapêuticas e adequado suporte nutricional, especialmente em populações mais vulneráveis e com maior risco genético e ambiental.

\section{REFERÊNCIAS BIBLIOGRÁFICAS}

ALEXANDER, K. L.; TARGAN, S. R.; ELSON, C. O. Microbiota activation and regulation of innate and adaptative immunity. Immunological Reviews. 260(1): 206-20, 2014.

BUTSCH, W. S.; HEIMBURGER, D. C. Malnutrition and disease outcomes. In: DeLEGGE, M. H. Nutrition and gastrointestinal disease. Totowa, NJ: Human Press, 2008.

COOK, G. C.; LAKIN, A.; WHITEHEAD, R. G. Absorption of lactose and its digestion products in the normal and malnourished Ugandan. Gut. 8: 622, 1967.

CROZIER, S. J.; D’ALECY, L. G.; ERNST, S. A.; GINSBURG, L. E.; Williams, J. A. Molecular Mechanisms of Pancreatic Dysfunction Induced by Protein Malnutrition. Gastroenterology. 137(3): 1093-101, 2009.

FERRARIS, R. P.; CAREY, H. V. Intestinal transport during fasting and malnutrition. The Annual Review of Nutrition. 20: 195-219, 2000.

HATCH, T. F.; LEBENTHAL, E.; KRASNER, J.; BRANSKI, D. Effect of postnatal malnutrition on pancreatic zymogen enzymes in the rat. The American Journal of Clinical Nutrition. 32(6): 1224-30, 1979.

KANE, A. V., DINH, D. M., WARD, H. D. Childhood Malnutrition and the Intestinal Microbiome Malnutrition and the microbiome. Pediatric Research. 77: 256-262, 2015.

KAU, A. L.; AHERN, P. P.; GRIFFIN, N. W.; GOODMAN, A. L.; GORDON, J. I. Human nutrition, the gut microbiome and the immune system. Nature. 474: 327-36, 2011.

MUNTHALI, T., JACOBS, C., SITALI, L., DAMBE, R., MICHELO, C. Mortality and morbidity patterns in under-five children with severe 
acute malnutrition (SAM) in Zambia: a five-year retrospective review of hospital-based records (2009-2013). Archives of Public Health. 73(1): 23, 2015.

MURPHY, J.L.; BADALOO, A.V.; CHAMBERS, B., FORRESTER, T. E.; WOOTTON, S. A.; JACKSON, A. A. Maldigestion and malabsorption of dietary lipid during severe childhood malnutrition. Archives of Disease in Childhood. 87(6): 522-5, 2002.

PETERSON, C. T.; SHARMA, C. T.; ELMÉN, L.; PETERSON S. N. Immune homeostasis, dysbiosis and therapeutic modulation of the gut microbiota. British Society for Immunology. Clinical and Experimental e Immunology. 179: 363-77, 2014.

RYTTER, M. J. H.; KOLTE, L.; BRIEND, A.; FRIIS, H.; CHRISTENSEN, V. B. The Immune System in Children with Malnutrition-A Systematic Review. PLoS ONE. 9(8): e105017, 2014.

WAPNIR, R. A. Zinc deficiency, malnutrition and the gastrointestinal tract. Journal of Nutrition. 130(Suppl 5S): 1388S-92S, 2000. 